\title{
Global Deforestation
}

Christiane Runyan and Paolo D'Odorico. 2016. ISBN 978-1107-13526-0. Cambridge University Press, Cambridge, UK. US $\$ 91.95$ (hard cover)+ shipping. Contact: egerney@cambridge.org

lobal Deforestation provides a concise 6 but comprehensive examination of the variety of ways in which deforestation modifies environmental processes, as well as the societal implications of these changes. The book stresses how forest ecosystems may be prone to nearly irreversible degradation. To prevent the loss of important biophysical and socioeconomic functions, forests need to be adequately managed and protected against the increasing demand for agricultural land and forest resources. The book describes the spatial extent of forests, and provides an understanding of the past and present drivers of deforestation. It presents a theoretical background to understand the impacts of deforestation on biodiversity, hydrological functioning, biogeochemical cycling, and climate. It bridges the physical and biological sciences with the social sciences by examining economic impacts and socioeconomic drivers of deforestation. This book will appeal to advanced students, researchers and policymakers in environmental science, ecology, forestry, hydrology, plant science, ecohydrology, and environmental economics.
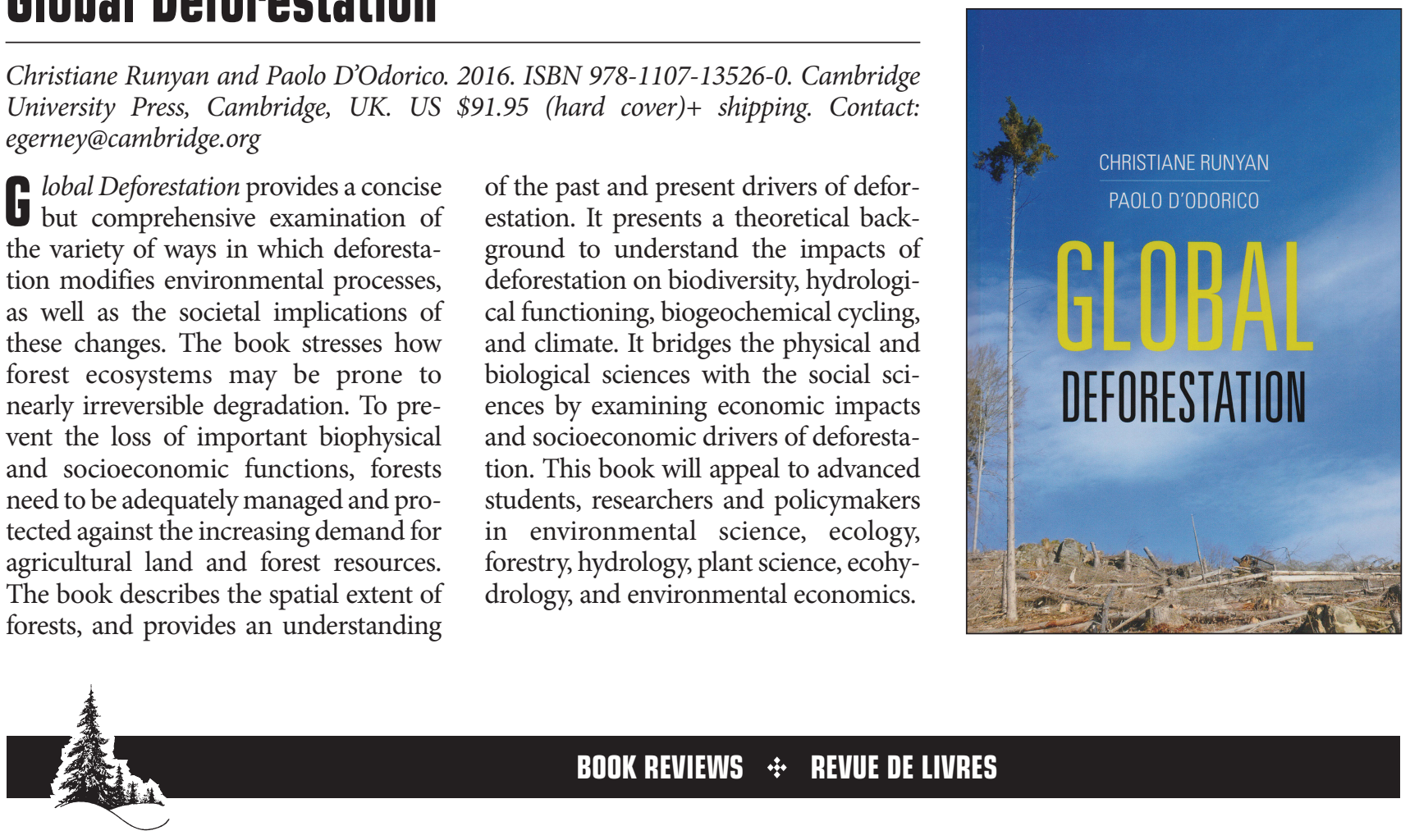

\section{Seeing Seeds - A Journey into the World of Seedheads, Pods, and Fruit}

Teri Dunn Chace. 2015. ISBN 978-1-60469-492-5 Thomas Allen \& Son, Markham, Ontario. 294 pgs. CAD \$39.95 + shipping. Contact:bonita.mok@t-allen.com

$\mathbf{T}^{\mathrm{h}}$ his is a beautifully illustrated book with photos created by "image stacking", a process which allows all parts of an object to be in sharp focus. The object, in this case a seed pod or fruit, is placed on a light table; several camera shots are taken from different angles and then pulled together using a special software program. The result is 'spectacular' pictures to illustrate the variability, complexities and often outright weirdness of the world of seeds and their various containers. Nothing is simple and straight-forward, and you wonder frequently why things are as they are. There are explanations of course-the seed is expected to float, drift on the wind, be eaten by birds or insects or transported by hitchhikers. They don't always explain "why things are so often complicated". Photographer Robert Llewellyn has more than 30 books featuring his work, including
Seeing Trees, selected as one of the best gardening books in 2011 by the New York Times.

Seeing Seeds is essentially divided into two sections. The first, for those of us who have forgotten our first-year Bio 110 , answers the questions-what are seeds, why do they exist, why are they so diverse, right up to what do seeds do and how do they do it. However, it is not only the seeds but their protective fleshy, papery or woody packaging that is so diverse and unusual. The text is by Teri Dunn Chace, author and editor of numerous articles on gardening and plant life. In this first section, she introduces some familiar terms such monoecious (male and female flower structures on the same plant) and dioecious (male and female flowers on separate plants). But then there is "apoximis" from the Greek, meaning "without intercourse"-also known as

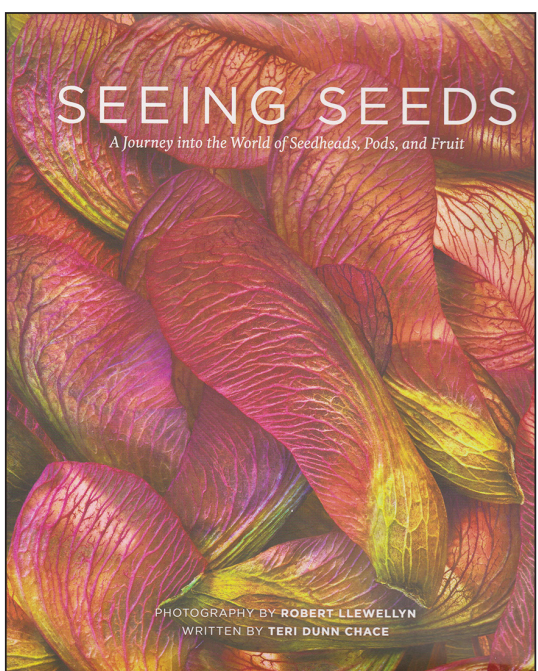

asexual reproduction. While this is a joyless situation, it is fortunately somewhat rare in nature. Some species of genera such as Crataegus, Amelanchier and Sorbus may indulge in this sad 